\title{
E-commerce applications in the tourism industry: A Tanzania case study
}

\author{
B-Y Chang ${ }^{\mathrm{a}}$, M.J. Magobe ${ }^{\mathrm{b}}$ and Y.B. Kim ${ }^{\mathrm{c}}$ \\ ${ }^{a}$ School of Business, Ajou University, Suwon, Korea \\ bDepartment of Graduate School of International Studies, Ajou University, Suwon, Korea \\ cDepartment of Management of Technology, Sungkyunkwan University, Suwon, Korea \\ *To whom all correspondence should be addressed \\ kimyb@skku.edu
}

\begin{abstract}
Tourism which is regarded as information intensive sector is the mostly affected sector by technology revolution and its traditional trading structures have been totally changed. The adoption and use of e-commerce in tourism sector is regarded as a tool to widen market reach and improve efficiency and effectiveness of business operations. The degree of impact of e-commerce use on business performance depends on the intensity of its usage in organization's key value-chain activities. However, the intensity of e-commerce use is influenced by technological, organizational and environmental (TOE) contextual factors. Based on TOE model and the existing literature on post-adoption use of e-commerce, a set of factors that affect the intensity of e-commerce use in Tanzanian tourism sector was identified. A survey was conducted with 181 Tanzanian tourism firms that have already adopted e-commerce and structural equation modeling (SEM) was used to analyze the data. The findings indicated that the scope of e-commerce use has a positive impact on business performance in terms of improved internal processes, competitive position, customer service delivery, overall business performance and increased customer base. The scope of e-commerce use is affected positively by pressure intensity and perceived benefits and negatively by barriers to e-commerce use. The findings have highlighted key areas that require immediate actions from both the government and private sector in order to promote a successful growth of e-commerce in the country.
\end{abstract}

\section{Introduction}

The emergence of e-commerce has impacted the way business is done across the world. The information technology (IT) revolution has had the greatest impact on tourism, an information-intensive industry, and has been applied to some sectors and some countries in the industry. Ecommerce has introduced new ways of performing tasks, interacting with customers, and conducting business (Quaddus \& Achjari, 2005). In this regard, e-commerce is considered to be a key driver of tourism firms in terms of facilitating global marketing, expanding the customer base, and improving productivity.

The adoption and use of e-commerce in the tourism industry has created new opportunities for introducing innovative business practices. The ability of e-commerce to reduce business costs and improve productivity is a key driver of its increasing adoption and use. Therefore, firms in the tourism industry that make use of IT innovations may strengthen their ability to increase the value of their products and services (Elly \& Boter, 2011). Given the opportunities created by globalization, the use of e-commerce can facilitate the expansion of markets at the global level by increasing the customer base and better serving existing customers.

The tourism industry is one of Tanzania's fastest-growing industries and accounts for approximately $12 \%$ of its gross domestic product (GDP) and $25 \%$ of earnings in foreign currencies (Lunogelo et al., 2009). To ensure sustained benefits, the industry needs to enhance its competitiveness by responding quickly to the fiercely competitive global tourism environment. IT innovation adoption have demonstrated that e-commerce can produce substantial cost reductions and serve as a source of competitive advantage because firms in the tourism industry can integrate various activities in their supply chain and offer personalized and enriched travel experiences.

Given the above discussion, this study examines the effects of technological, organizational, and environmental factors on the scope and the effect of e-commerce use on firm performance. In this regard, the study is guided by the following key research questions:

1: What factors do influence the intensity of post-adoption e-commerce use within firms in the Tanzanian tourism industry?

2: How does the intensity of e-commerce use influence firm performance?

\section{Literature review}

\section{E-commerce use and its determinants}

Tetelman (2000) defined e-commerce as any economic or business activity that uses Information Communication Technology (ICT)-based applications in its transactions. Barkley et al. (2007) broadly defined e-ecommerce as "marketing, selling and buying over the Internet (e-tailing), business-to-business electronic data interchange (EDI), conducting research and seeking information, emailing and computer faxing, internal information networks for 
employees and ensuring the security of on-line transactions and information transfers." E-commerce is used not only for buying and selling but also for a wide range of pre-sales efforts (Gunasekaran and Ngai, 2005).

The evolution of web technologies has facilitated the adoption and use of e-commerce by a wide range of users, from the largest firms to the smallest, which levels the playing field. The widespread adoption and increased use of the web for e-commerce are driven by IT sophistication as well as by lower web-related costs (Pflughoeft et al., 2003).

Yuan et al. (2003) used the number of years an organization has used internet applications and the number of internet applications an organization uses to define e-commerce use. Kraemer et al. (2005) measured the extent of e-commerce use in terms of the type of use (e.g., B2B and B2C) and the scope of use, and Gibbs and Kramer (2010) defined it as the extent to which e-commerce is used in various values chain activities.

Other studies focusing on the post-adoption use of ecommerce in retailers, service providers, and manufacturers in developed countries have determined that contextual factors (e.g., technological competence, financial commitment, firm size, the firm's scope, competitive pressure, regulatory support/barriers, the readiness of partners, and investment costs) and four innovative characteristics (relative advantages/perceived benefits, compatibility, costs, and security concerns) are important predictors of the intensity of e-commerce use (Zhu and Kraemer, 2005), (Gibbs and Kramer, 2010), (Salwani et al., 2009). Firms with higher perceived benefit ratings for ecommerce use are more likely to incorporate various applications into their work (Yuan et al., 2003), (Gibbs and Kraemer, 2010). Additionally, the economic environment can shape the effects of these factors (Zhu \& Kraemer, 2005), (Zhu et al., 2006).

Previous studies have reported mixed results regarding the relation between e-commerce use and investment costs. Zhu et al. (2006) found a negative relationship between investment costs and e-commerce use, whereas Salwani et al. (2009) found a positive relationship. However, Fuchs et al. (2010) suggested that neither costs nor any other financial aspects influence the intensity of e-commerce use.

Quaddus and Achjari (2005) attributed the intensity of ecommerce use to the availability of expertise, the level of risk, and convenience. Firms with a higher proportion of workers with a college/university degree are more likely to show a high level of e-commerce intensity (Vicente \& Lopez, 2009).

Further, globalization has had considerable influence on the scope of e-commerce use. For global firms, the adoption and use of e-commerce makes it easier and cheaper to expand their market presence across borders. Kraemer et al. (2005) suggested that highly global firms are more likely to engage in e-commerce in response to foreign competition and the operational need to reduce transaction costs and coordinate activities across national borders.

\section{Effects of e-commerce on firm performance}

The availability of relatively inexpensive information delivery mechanisms enables firms to improve their performance because they can better maintain their relationships with customers, particularly for value-added services and support (Tetelman, 2000). E-commerce adoption and use in firms in the tourism industry not only can help them increase their cost-effectiveness but also can improve their coordination of activities with business partners (Pflughoeft, 2004), (Zhu \& Kraemer, 2005), (Zhu et al., 2006), (Molla and Heeks, 2007), (Salwani et al., 2009).

Additionally, e-commerce reinforces firms' competitive advantage by helping them to expand markets across borders and by reducing entry barriers. It can also provide new opportunities and tools for meeting customers' needs (Kourtit et al., 2011). The importance of e-commerce goes beyond the facilitation of transactions; it can play a vital role in retaining customers and increasing profitability. Indeed, Prewitt (2002) found that a $5 \%$ increase in customer retention resulted in a $25-29 \%$ increase in profits.

Many studies have quantified effects of e-commerce using either financial measures such as profitability, cost reductions, and inventory efficiency (Zhu \& Kraemer, 2002) or nonfinancial ones (Kraemer et al., 2005), (Mola \& Heeks, 2007), (Zhu \& Kraemer, 2005). Some have considered various combinations of these two types of measures (see Zhuang \& Lederer, 2006), (Salwani et al., 2009). Nonfinancial measures of e-commerce value include the efficiency of operations, improvements in business relationships, market growth (Pflughoeft et al., 2003), (Zhu and Kraemer, 2005), (Zhu et al., 2006), (Fuchs et al., 2010), contributions of e-commerce to the achievement of organizational goals, the number of visitors to a particular site, the amount of time visitors spend on a particular site (Quaddus \& Achjari, 2005), strategic benefits (Pflughoeft, 2003), the number of applications used (Yuan et al., 2003), and competitive advantage (Elly \& Boter, 2011).

Furthermore, previous studies of the business value of ecommerce have suggested that the intensity of e-commerce use and e-commerce capabilities such as front-end functionalities and back-end integration have some influence on e-commerce benefits (Zhu et al., 2006), (Salwani et al., 2009), (Fuchs et al., 2010), (Zhu \& Kraemer, 2005), (Molla \& Heeks, 2007). Molla and Heeks (2007) have explained efficiency as improvements in the coordination of supply chain and economic activities (market and operational efficiency).

Value creation through IT innovation depends on IT, business, and human resources (Zhuang \& Lederer, 2005), (Elly \& Boter, 2010). In this regard, combining internet characteristics such as open standard, public network and global connectivity with IT, business, and human resources may provide firms with opportunities to improve their performance. 
The model of e-commerce success developed by Quaddus and Achjari (2005) identifies internal and external drivers and barriers as key factors influencing e-commerce success. Internal and external drivers, which are generally defined as the benefits perceived or expected by an organization and its business partners as a result of the organization's e-commerce use, can facilitate e-commerce success. In contrast, internal and external barriers, which are generally defined as constraints perceived to be likely by an organization and its business partners in the use of e-commerce, can hinder ecommerce success.

\section{Theoretical background}

A wide range of models to examine the determinants of organizations' adoption and use of technological innovations in their operations are reported. Most studies have employed adoption models such as the technology acceptance model (TAM) (see Maswera et al., 2008) and the technologyorganization-environment (TOE) model (Gibbs and Kraemer, 2010). Others have combined several models into one framework, such as the TAM and the diffusion of innovations (DOI) (see Hung et al., 2011), or the TAM, the theory of planned behaviour (TPB), and the DOI (Cheng and Cho, 2010).

Various studies have focused on the predictors of technology adoption, but few have accounted for post-adoption effects. Zhu and Kraemer (2005) were the first to address this gap in the literature by combining the TOE model with the resourcebased view (RBV) to assess the use and value of e-commerce in organizations (Salwani et al., 2009). A number of studies have employed this model (see Fuchs et al., 2010), (Salwani et al., 2009), (Zhu et al., 2006) to examine the effects of technological, organizational, and environmental factors on e-commerce use and the effect of this use on firm performance. In the framework, the authors extended the use of the TOE model by considering the relationship between ecommerce use and firm performance.

Furthermore, it has been reported that the relationship between e-commerce use and firm performance based on the fact that value creation through e-commerce depends on the extent to which e-commerce is used by organizations. An increase in e-commerce use can strengthen an organization's rare, inimitable, valuable, and sustainable IT capabilities (Zhu et al., 2006), that is, the greater the e-commerce use, the greater the likelihood that an organization creates ecommerce capabilities that can contribute to its performance. Thus, it is important to examine the effectiveness of ecommerce use in emerging markets. Previous studies have examined the use of e-commerce and its benefits to firms based on the TOE framework. The TOE model, developed by Tornatzky and Fleischer (1990), identifies three aspects of the firm's context that influence the adoption, implementation, and use of a technological innovation: technological, organizational, and environmental contexts.

These three contextual factors can impact the way a firm searches for, adopts, and uses e-commerce. Although many studies have used the TOE model to examine ICT and ecommerce adoption, they have typically combined it with other theories to investigate the intensity of e-commerce use and the value of e-commerce for e-commerce adopters. In addition, some studies have combined the TOE model with other theories to examine the intensity of e-commerce use and value creation through e-commerce, including the RBV (Zhu and Kraemer, 2005), (Salwani et al., 2009), the DOI (Zhu et al., 2006), and both the DOI and the RBV (Hung et al., 2011). This study was guided by TOE model to examine the relationship between e-commerce use and firm performance and the interaction between the factors influencing both the intensity of e-commerce use and firm performance.

\section{Hypothesis}

Both internal and external factors can influence an organization's decision to adopt and continuously use a particular technological innovation. Pressure from competitors, customers, and key suppliers represents an important external driver. Previous studies have suggested that an increase in market pressure makes it more likely for a firm to increase its use of technological innovations to enhance its responsiveness to market changes and its delivery of customer service (Zhu et al., 2006). In this regard, the following hypothesis is proposed about the effect of pressure intensity on e-commerce use:

\section{H1: Pressure intensity has a positive effect on the scope} of e-commerce use.

Previous studies have suggested that perceived benefits represent one of the TOE factors that influence the intensity of e-commerce use in firms of various industries (Gibbs and Kraemer, 2010), (Zhu et al., 2006). Some studies have described perceived benefits in terms of a firm's efforts to increase its customer base by entering new markets and expanding existing ones as well as to achieve cost reductions and better coordination with suppliers and customers. Firms can achieve these goals by making increased use of ecommerce. In this regard, the following hypothesis is proposed:

H2: Perceived benefits of e-commerce use have a positive effect on the scope of e-commerce use.

Technological competence is a firm's ability to evaluate, assimilate, and apply new knowledge (Vicente and Lopez, 2009). The endowment of human resources with technical and managerial skills in IT is one of the key factors influencing this competence (Kuang \& Xu, 2008). A firm's technical knowledge and skills with respect to IT innovations provide it with the ability to build IT applications by using available technologies and use them to facilitate information gathering, transactions, and fulfilment/customer service efforts. Therefore, firms with personnel with relevant IT knowledge and skills may have relevant skills for technological competence and thus may exhibit a greater propensity to use e-commerce applications (Bresnahan et al., 
2002), (Kuang \& Xu, 2008), (Quaddus \& Achjari, 2005). In this regard, the following hypothesis is proposed:

\section{H3: Technological competence has a positive effect on the scope of e-commerce use.}

Firms fail to make extensive use of technologies they adopt for various reasons. Security concerns, web technology investments, operating costs (cost of developing and maintaining e-commerce systems), and a lack of regulatory frameworks for supporting online transactions are important inhibitors to both e-commerce use and subsequent value creation through e-commerce at the firm level. For example, Zhu et al. (2006) found that costs have a significant negative effect on e-commerce use.

Security concerns have received increasing attention from ecommerce researchers in recent years. Security risks associated with online transactions have a considerable negative effect on e-commerce diffusion. Therefore, security risks such as unauthorized access to data, fraud, viruses, and service denial can spoil a firm's reputation and cause serious damage, even the loss of the whole database. The Organization for Economic Cooperation and Development (OECD, 2004) pointed out that privacy and legal protection for internet purchases are two major barriers to internet use in business transactions in Singapore, Brazil, and China. Gibbs and Kraemer (2010) found that regulatory barriers reduce the scope of e-commerce use. These effects may limit the use of e-commerce by all parties involved in online transactions. In this regard, the authors proposed the following hypothesis:

H4: Barriers to e-commerce use have a negative effect on the scope of e-commerce use.

\section{Relationship between e-commerce use and business performance}

Tourism is an information-intensive industry and the use of e-commerce can enhance a firm's competitiveness and increase its operational efficiency. Zhuang and Lederer (2006) argued that e-commerce influences organizational performance by expanding distribution channels, fostering new marketing communication media, and enhancing operational efficiency. The effect of a new technology on firm performance depends on the extent to which the technology is used in the organization's key value chain (Zhu et al., 2006). Recent studies have shown that e-commerce use has a significant positive effect on firm performance (Kraemer et al., 2005), (Zhu \& Kraemer, 2005), (Zhu et al., 2006), (Salwani et al., 2009), (Fuchs et al., 2010). In this regard, to determine whether the intensity of e-commerce use has a significant positive effect on firm performance, the following hypothesis is proposed:

H5: An increase in the scope of e-commerce use increases the value of e-commerce.

Basing on the TOE model, a structural equation model (Fig.1) was developed to examine the relationship between e- commerce use and firm performance and the interaction between the factors influencing both the intensity of ecommerce use and firm performance. The proposed model is an extension of Gibbs and Kraemer (2010) because it also considered the relationship between the scope of e-commerce use and firm performance.

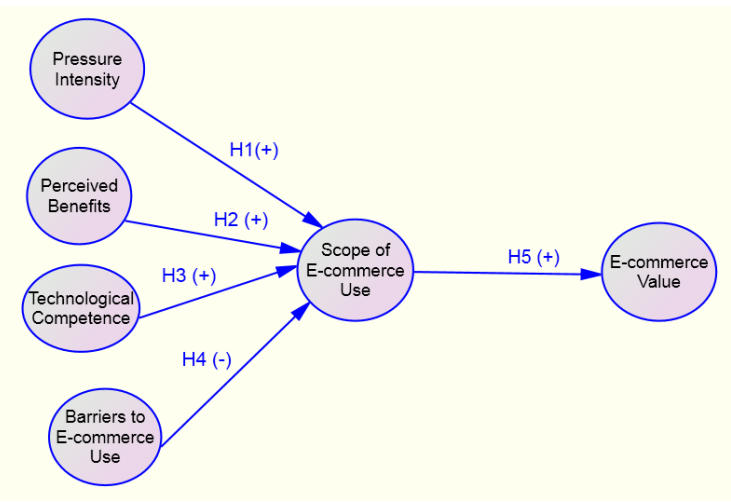

Figure 1: Initial structural model of e-commerce value

The improvements are based on previous studies of the adoption and use of e-commerce in developing countries where its use is still in the initial stages and there are no welldeveloped laws and regulatory framework for promoting ecommerce growth (Table 1).

Table 1: Proposed improvements to Gibbs and Kraemer's (2010) model

\begin{tabular}{l|l}
\hline Improvements & Explanation \\
\hline External Pressure & $\begin{array}{l}\text { The model's measurement scale for } \\
\text { external pressure is not comprehensive } \\
\text { from the perspective of pressure } \\
\text { intensity. Therefore, this study adds one } \\
\text { indicator (pressure from suppliers) to the } \\
\text { measurement scale. }\end{array}$ \\
\hline Barriers to E- & $\begin{array}{l}\text { A set of barriers influences e-commerce } \\
\text { use in developing countries. Previous } \\
\text { studies have indicated that barriers to e- } \\
\text { commerce Use } \\
\text { regulatory barriers but also financial and } \\
\text { technological ones. Therefore, this study } \\
\text { replaces regulatory barriers with barriers } \\
\text { to e-commerce use and adds additional } \\
\text { indicators to the measurement scale to } \\
\text { better reflect regulatory, financial, and } \\
\text { technological constraints. }\end{array}$ \\
\hline Technological & $\begin{array}{l}\text { This study uses technological } \\
\text { competence instead of technological } \\
\text { resources. Given that most firms have }\end{array}$ \\
access to the Internet, technological \\
competence
\end{tabular}


Additionally, the authors excluded two constructs in Gibbs and Kraemer's (2010) model from the proposed model, namely firm size and a lack organizational compatibility, because previous studies have found that they have no significant effects on the intensity of e-commerce use (Gibbs \& Kraemer, 2010), (Salwani et al., 2009).

The Tanzanian tourism industry is dominated by small and medium-sized enterprises (SMEs) and thus firm size is likely to have little effect on the intensity of e-commerce use because a majority of these firms are of the same size. The indicators for this lack of organizational compatibility in the Gibbs and Kraemer's (2010) model are almost the same as indicators for barriers to e-commerce use and technological competence. Therefore, lack of organizational compatibility construct was excluded from the proposed model.

Finally, based on a confirmatory factor analysis (CFA) of the measurement model, one exogenous factor was excluded (technological competence) because its observed variables were not significant. As a result, the revised model of ecommerce value (Figure 2) was composed of three exogenous constructs and two endogenous ones.

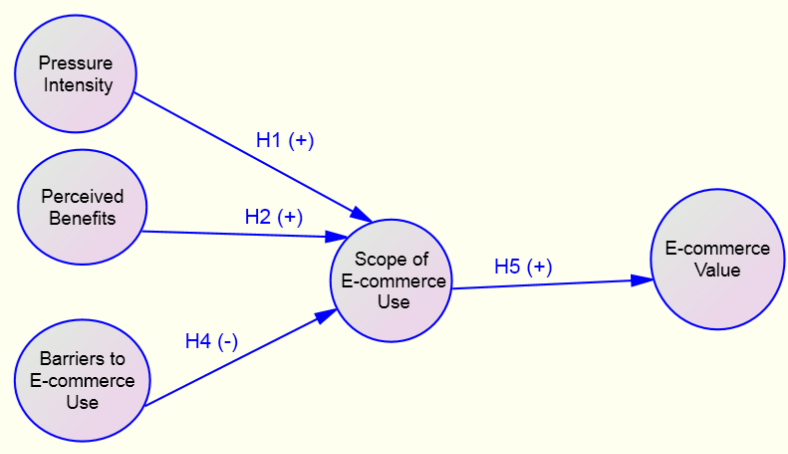

Figure 2:Revised structural model of e-commerce value

\section{Measurement models}

Each construct in the hypothesized model, having been selected based on the literature review, had at least two indicators. The study employed a five-point Likert-type scale ranging from "strongly disagree" (1) to "strongly agree" (5) for each indicator. Yoon (2002) suggested that when the relationships between observed indicators and constructs are uncertain or unknown, it is imperative to conduct an exploratory factor analysis (EFA) before a CFA, and he recommended the evaluation and re-specification of the confirmatory measurement model before any simultaneous examination of measurement and structural equation models.

\section{Methodology}

The authors obtained a list of firms in the tourism industry from the Tourism Confederation of Tanzania (TCT) and the Tanzania Tourist Board. As of April, 2012, Tanzania Tourist Board maintained a database of more than 597 travel and tour operators. In addition, the 2012 directory of Tanzania Travel and Tourism revealed a list of 46, 14, 60 and 100 registered members under Hotel Association of Tanzania, Tanzania Air Operators Association, Tanzania Hunting Operators Association and Zanzibar Association of Tourism Investors respectively. The population is therefore made up of 819 firms. The selection of a sample of these firms was based on two criteria: the presence or ownership of a website and 5100 employee base. The intention was to select firms which had already adopted e-commerce, the proposition being that these firms exhibited higher degree of e-commerce usage and thus improved their business performance resulting from ecommerce applications. The data for the survey were collected by using both online and offline methods. The authors distributed a total of 378 questionnaires in six cities by personal delivery and obtained 145 responses. A total of 175 questionnaires were also distributed online to firms in other cities and places and 36 responses were obtained. A structural equation modeling (SEM) approach was employed to analyze the data and test the hypotheses. Yoon (2002) observed that SEM can be used to evaluate the fit of the proposed conceptual model with observed indicators and constructs to the data. SEM is a confirmatory approach to the analysis of a structural theory for some phenomenon. The legitimacy of taking a confirmatory approach to test a model's fit to given data must be based on theory, empirical research, or both (Byrne, 2001).

The measurement model was tested through a CFA and SEM was employed to test the hypotheses. The maximum likelihood (ML) method was used to estimate the parameters of the hypothesized model. SPSS 17.0 was used for conducting EFA and estimation of the reliability of measurement scales. The authors used AMOS 17.0 to conduct the CFA and test the hypotheses.

For the sample, the authors considered firms in the Tanzanian tourism industry that engaged in e-commerce. Only one questionnaire was distributed to each organization and highprofile personnel were target respondents. A total of 553 questionnaires were distributed and yielded 181 responses (32.7\% response rate). It was established that positions of most respondents were CEO, marketing managers, administration managers, information systems managers and business operations managers. In terms of respondents, $38.5 \%$ were hotels and restaurants, $27.4 \%$ tour operators, $20.6 \%$ travel agents, $5.2 \%$ airlines and $8.3 \%$ were other firms such as hunting companies and those providing services indirectly to the industry. The authors excluded 12 responses because of missing data and thus had a final sample of 169 responses for the analysis.

The reliability (the extent to which items are inter-correlated or measure the same thing) was measured by using Cronbach's alpha. In general, an alpha value greater than or equal to 0.70 is acceptable and indicates sufficient internal consistency for the measurement scale, but less than 0.70 indicates insufficient internal consistency (Yoon \& Uysal, 2005). In this study, Cronbach's alpha exceeded this threshold for all five constructs, ranging from 0.86 to 0.91 . 
Table 2: Reliability of constructs (Cronbach's Alpha)

\begin{tabular}{l|c|c}
\hline Measurement Scale & $\begin{array}{l}\text { Number of } \\
\text { Indicators }\end{array}$ & $\begin{array}{l}\text { Cronbach's } \\
\text { Alpha ( } \boldsymbol{\alpha})\end{array}$ \\
\hline Pressure Intensity & 3 & 0.889 \\
\hline Perceived Benefits & 4 & 0.91 \\
\hline $\begin{array}{l}\text { Barriers to E- } \\
\text { commerce Use }\end{array}$ & 4 & 0.877 \\
\hline $\begin{array}{l}\text { Technological } \\
\text { competence }\end{array}$ & 2 & 0.808 \\
\hline $\begin{array}{l}\text { Scope of E-commerce } \\
\text { Use }\end{array}$ & 4 & 0.863 \\
\hline E-commerce Value & 5 & 0.924 \\
\hline
\end{tabular}

The content validity (the accuracy with which a measure represents a construct) was verified by having the measurement scales examined by one ICT scholar, one ICT practitioner, and four firms in the tourism industry. Based on their comments, views and suggestions, appropriate changes to the measurement scales were made.

The empirical evidence of validity was obtained by considering convergent and discriminant validity. Convergent validity refers to the extent to which items converge to their intended constructs. Convergent validity was evaluated by using the criteria proposed by Bagozzi and Philips (1982), including the criterion that factor loadings of observed variables for the same construct must be greater than or equal to 0.70 and significant in the CFA of the measurement model. As shown in Table 5, the results of the CFA indicated that all standardized factor loadings exceeded this threshold and that the critical ratios of all observed variables were significant at the 0.05 level. Discriminant validity indicates the extent to which measures of various concepts are unrelated to one another. As shown in Table 3, all average variance extracted (AVE) estimates exceeded the corresponding squared inter-construct correlation estimates, indicating sufficient discriminant validity.

Table 3: Average variance extracted and squared interconstruct correlation estimates

\begin{tabular}{l|c|c|c|c|c|c}
\hline & AVE & PR & PB & BR & SC & EV \\
\cline { 1 - 5 } PR & 0.7327 & & & & & \\
\cline { 1 - 1 } PB & 0.6435 & 0.003 & & & & \\
\cline { 1 - 1 } BR & 0.728 & 0.001 & 0.0142 & & & \\
\cline { 1 - 1 } SC & 0.6143 & 0.054 & 0.0276 & 0.0404 & & \\
\hline
\end{tabular}

\section{Exploratory factor analysis}

For the case in which the relationships between observed indicators and constructs are uncertain or when constructs are new, Yoon (2002) and Pflughoet et al. (2003) recommended an EFA before a CFA to identify the underlying constructs and investigate the relationships between indicators.
In order to evaluate factor loadings and identify the underlying factors, a principal component analysis with Varimax rotation was conducted. In this study, an eigenvalue greater than or equal to 1.0 and a factor loading of 0.30 were the benchmarks for the inclusion of an item in its proposed factor (Yoon, 2002). Items 11, 17, and 20 loaded poorly on their proposed factors, and therefore, were excluded from the analysis. The authors then conducted another EFA and the results (Table 4) indicated that all factor loadings exceeded 0.70 (total variance explained $=78.2 \%$; Kaiser-Meyer-Olkin $=0.79)$.

Table 4: Factor loadings of constructs (EFA)

\begin{tabular}{l|l|l|l|l|l|l}
\hline & \multicolumn{5}{|c}{ Component } \\
\hline & 1 & 2 & 3 & 4 & 5 & 6 \\
\hline PR1 & .912 & & & & & \\
PR2 & .872 & & & & & \\
PR3 & .905 & & & & & \\
PB4 & & .829 & & & & \\
PB5 & & .862 & & & & \\
PB6 & & .865 & & & & \\
PB7 & & .848 & & & & \\
TC8 & & & .908 & & & \\
TC9 & & & .901 & & & \\
BR10 & & & & .818 & & \\
BR12 & & & & .914 & & \\
BR13 & & & & .927 & & \\
BR14 & & & & .864 & & \\
SC15 & & & & & .809 & \\
SC16 & & & & & .811 & \\
SC18 & & & & & .831 & \\
SC19 & & & & & .833 & \\
EV21 & & & & & & .815 \\
EV22 & & & & & & .853 \\
EV23 & & & & & & .889 \\
EV24 & & & & & & \\
EV25 & & & & & & \\
\hline
\end{tabular}

Confirmatory factor analysis for the measurement model

Yoon (2002) recommended a two-step CFA if testing was based on the premise that observed variables were not perfect indicators of underlying constructs. Here, in the first step, the measurement model for each construct was tested separately. Given an acceptable measurement model, the overall measurement model was tested.

In this study, the measurement model for exogenous constructs was re-specified and evaluated as a CFA measurement model. As a result, the technological competence construct was dropped because the factor loadings of its observed variables were not significant. Then a CFA was conducted for the measurement model for each endogenous factor (the scope of e-commerce and ecommerce value). Finally, the acceptable measurement model (with modifications) was re-specified for all constructs as a CFA measurement model for an overall test of the model. Table 5 and 6 show the results of the final CFA (after modifications) for the overall measurement model. 
The results for the measurement model generally indicated acceptable goodness-of-fit indices: $\chi^{2} / \mathrm{df}=1.338$, $\mathrm{AGFI}=0.863, \mathrm{CFI}=0.976, \mathrm{NFI}=0.914, \mathrm{IFI}=0.977$, RMSEA $=0.045$ (except for $\mathrm{RMR}=0.052$, GFI=0.899). The factor loadings were reasonable and significant, and squared multiple correlations (SMCs) ranged from 0.49 to 0.85 . These results indicated that the re-specified measurement model provided the best fit of the data.

Table 5: Results of the CFA for the overall measurement model

\begin{tabular}{|c|c|c|c|c|c|c|}
\hline Construct & Indicator & $\begin{array}{l}\text { Unstandardized } \\
\text { Loadings }\end{array}$ & $\begin{array}{l}\text { Standardized } \\
\text { Loadings } \\
\end{array}$ & SE & CR & SMC \\
\hline \multirow{3}{*}{ PR } & PR1 & 0.901 & 0.86 & 0.066 & 12.59 & 0.739 \\
\hline & PR2 & 0.949 & 0.805 & 0.075 & 13.76 & 0.649 \\
\hline & PR3 & 1.00 & 0.9 & 0.000 & 0.000 & 0.81 \\
\hline \multirow{4}{*}{ PB } & PB4 & 0.987 & 0.700 & 0.095 & 10.41 & 0.49 \\
\hline & PB5 & 1.041 & 0.842 & 0.106 & 9.853 & 0.71 \\
\hline & PB6 & 1.141 & 0.880 & 0.111 & 10.24 & 0.774 \\
\hline & PB7 & 1.00 & 0.720 & 0.000 & 0.000 & 0.519 \\
\hline \multirow[t]{4}{*}{$\mathrm{BR}$} & BR10 & 0.942 & 0.761 & 0.82 & 11.51 & 0.578 \\
\hline & BR12 & 1.002 & 0.887 & 0.070 & 14.29 & 0.787 \\
\hline & BR13 & 0.998 & 0.915 & 0.065 & 15.38 & 0.837 \\
\hline & BR14 & 1.00 & 0.842 & 0.000 & 0.000 & 0.71 \\
\hline \multirow[t]{3}{*}{$\mathrm{SC}$} & SC16 & 0.995 & 0.773 & 0.099 & 10.04 & 0.597 \\
\hline & SC18 & 1.00 & 0.797 & 0.000 & 0.000 & 0.635 \\
\hline & SC19 & 1.066 & 0.855 & 0.101 & 10.582 & 0.732 \\
\hline \multirow{5}{*}{ EV } & EV21 & 1.00 & 0.772 & 0.000 & 0.000 & 0.596 \\
\hline & EV22 & 1.082 & 0.822 & 0.093 & 11.595 & 0.675 \\
\hline & EV23 & 1.158 & 0.856 & 0.096 & 12.031 & 0.732 \\
\hline & EV24 & 1.125 & 0.877 & 0.091 & 12.33 & 0.769 \\
\hline & EV25 & 1.128 & 0.884 & 0.101 & 12.328 & 0.781 \\
\hline
\end{tabular}

Goodness-of-fit indices

\begin{tabular}{l|l|l|l|l|l|l|l|l|l|l}
\hline$\chi^{\mathbf{2}}$ & DF & $\boldsymbol{p}$ & $\chi^{\mathbf{2} / \mathbf{d f}}$ & RMR & GFI & AGFI & CFI & NFI & IFI & RMSEA \\
\hline 188.64 & 141 & 0.005 & 1.338 & 0.052 & 0.899 & 0.883 & 0.976 & 0.914 & 0.977 & 0.045 \\
\hline
\end{tabular}

Note: Items BR10, BR12, BR13 and BR14 were reverse-coded.

Table 6: Goodness-of-fit indices

\begin{tabular}{l|l|l|l|l|l|l|l|l|l|l}
\hline$\chi^{\mathbf{2}}$ & df & $\boldsymbol{p}$ & $\chi^{\mathbf{2} / \mathbf{d f}}$ & RMR & GFI & AGFI & CFI & NFI & IFI & RMSEA \\
\hline 190.12 & 144 & 1 & 1.32 & 0.055 & 0.898 & 0.865 & 0.977 & 0.913 & 0.977 & 0.044 \\
\hline
\end{tabular}

\section{Fit of the structural equation model}

As shown in Table 7, all goodness-of-fit indices except for the RMR and the GFI were within acceptable limits. The ratio of $\chi^{2}$ to the degrees of freedom was less than the acceptable threshold of $3.0\left(\chi^{2} / \mathrm{df}=1.320\right)$. The CFI $(0.977)$ and the IFI (0.977) exceeded the acceptable threshold of 0.95 . The NFI (0.913) exceeded the acceptable threshold of 0.90 , and the
RMSEA (0.044) was under the recommended threshold of 0.08 . The RMR was slightly above the required threshold of $0.05(\mathrm{RMR}=0.055)$, and the GFI was slightly below the acceptable threshold of 0.90 ( $\mathrm{GFI}=0.898)$. However, the AGFI was 0.865 , slightly exceeding the acceptable threshold of 0.86 . These results indicate that the model generally provided a reasonable fit of the data.

\section{Table 7: Results of hypothesis testing}

\begin{tabular}{ll|l|l|l|l}
\hline Hypotheses & & Parameter Estimates & C.R. & $\boldsymbol{p}$ & Results \\
\hline $\mathrm{PR}$ & $\rightarrow$ & $\mathrm{SC}(\mathrm{H} 1)$ & 3.151 & 0.002 & Supported \\
$\mathrm{nnB}$ & $\mathrm{SC}(\mathrm{H} 2)$ & 0.276 & 2.482 & 0.013 & Supported \\
\cline { 3 - 8 } $\mathrm{BR}$ & $\mathrm{SC}(\mathrm{H} 4)$ & -0.233 & -2.814 & 0.005 & Supported \\
$\mathrm{n}$ & $\mathrm{EV}(\mathrm{H} 5)$ & 0.182 & 2.978 & 0.003 & Supported \\
\hline
\end{tabular}

Note: $\mathrm{PR}=$ Pressure intensity; $\mathrm{PB}=$ Perceived benefits; $\mathrm{BR}=$ Barriers to ecommerce use; $\mathrm{SC}=\mathrm{Scope}$ of e-commerce use; EV=E-commerce value. 


\section{Results of hypothesis testing}

As shown in Figure 3 (standardized parameter estimates) (unstandardized parameter estimates), the results of the tested hypotheses were satisfactory in terms of their feasibility and significance and the appropriateness of standard errors. The estimated parameters showed signs that were consistent with the hypotheses. The critical values of all regression coefficients exceeded the acceptable limit $( \pm 1.96)$ at the 0.05 level, indicating their significance. Pressure intensity $(\mathrm{H} 1)$ $(\gamma 1=0.261, p \leq 0.05)$, perceived benefits $(\mathrm{H} 2)(\gamma 2=0.276, p$ $\leq 0.05)$, and barriers to e-commerce use $(\mathrm{H} 4)(\gamma 4=-0.233, \mathrm{p}$ $\leq 0.05)$ were significant predictors of the scope of ecommerce use. Additionally, the scope of e-commerce use had a positive effect on firm performance $(\mathrm{H} 5)(\beta 21=0.182)$. In this regard, these results supported the four hypotheses.

Overall, the three exogenous factors together explained $16.1 \%$ of the variance in the intensity of e-commerce use $\left(\mathrm{R}^{2}\right.$ $=0.161)$. The scope of e-commerce use explained $6.9 \%$ of the variance in e-commerce value $\left(R^{2}=0.069\right)$.

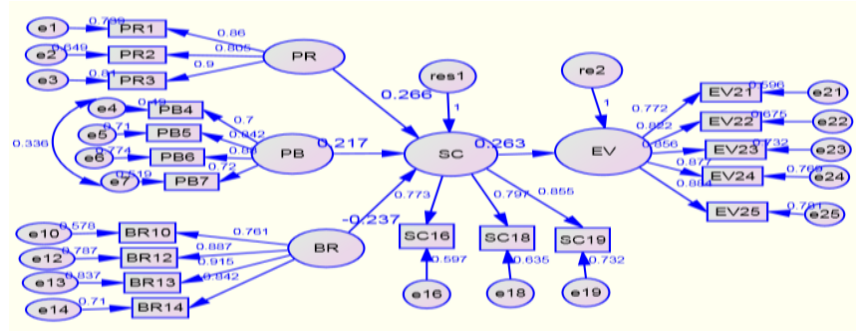

Figure 3: Structural equation model

\section{Discussion and implications}

The SEM results indicate that pressure intensity and perceived benefits had positive effects on the scope of ecommerce use, whereas barriers to e-commerce use had a negative effect. Additionally, there was a positive relationship between the scope of e-commerce use and firm performance.

The authors considered the types of activities for which the respondents used the internet and found that most used it mainly for marketing/advertising, exchanging information with customers, and online sales, but not for purchases or exchanging information with suppliers. This implies that respondents used e-commerce mainly to attract and retain customers, which is an important strategy for gaining a competitive edge over competitors (Sulaiman, 2000). However, this imbalanced use of e-commerce in business is likely to reduce its impact on firm performance. Therefore, managers of firms in the tourism industry should consider the possibility of striking a balance between these two sides to better realize the full potential value of e-commerce.

It was also found that pressure intensity had a significant positive effect on the scope of e-commerce use (H1). This suggests that an increase in pressure intensity can induce firms in the tourism industry to intensify their use of e- commerce to better respond to market changes as well as to increase the customer base and improve coordination with key suppliers. The finding of a significant relationship between pressure intensity and the scope of e-commerce use is consistent with previous findings (Salwani et al., 2009), (Gibbs \& Kraemer, 2010), (Zhu and Kraemer, 2005), (Zhu et al., 2006).

The SEM results also indicate a significant relationship between perceived benefits and the scope of e-commerce use (H2). This suggests firm's efforts to increase their customer base by creating new markets, achieving cost reductions, and improving relationships with suppliers and customers may lead to the increased use of e-commerce, which is consistent with previous findings (Gibbs \& Kraemer, 2010), (Zhu et al., 2006).

However, it was also found that annual operating costs, security concerns, and a lack of regulatory support for online transactions had significant negative effects on the intensity of e-commerce use (H4).

Although the Tanzanian government has implemented appropriate policies to facilitate e-commerce use by removing all taxes and duties on computers and peripherals, the annual operating cost of e-commerce remains high in the country, partly because firms providing data communications services (including internet bandwidth) have isolated initiatives for connecting their points of presence (PoPs) to the global internet backbone. As a result, Tanzania lacks low-cost and high-capacity connections to the global Internet (Government of Tanzania, 2003).

Security concerns had a significant negative effect on the intensity of e-commerce use. This suggests that a lack of data security and privacy makes it difficult for individuals and firms to engage extensively in online transactions. A low level of trust in online transactions is due to the fact that existing legal frameworks do not provide sufficient safeguards to create environments facilitating trust in ecommerce transactions (Government of Tanzania, 2003). Buyers and sellers are likely to engage in online transactions if they know that their rights and obligations will be legally enforced. Building trust is an important precondition for ecommerce and without it; any efforts to promote e-commerce use are likely to fail (Almeida de Almeida et al., 2007). For this reason, managers in the tourism industry should not avoid e-commerce but find ways to maximize its benefits. -

There was a positive relationship between the scope of ecommerce use and firm performance (H5). This result suggests that firms in the tourism industry are likely to realize e-commerce benefits and imply that the use of e-commerce for marketing/advertising, sales, and information exchanges with customers can improve their competitiveness and overall firm performance. This suggests that managers who are already using the Internet for business transactions should intensify its use in their operations to realize more ecommerce opportunities. These results are consistent with previous studies (Salwani et al., 2009), (Zhu and Kraemer, 2005), (Zhu et al., 2006). 
The findings also indicate that technological competence was not an important predictor of the scope of e-commerce use, which is inconsistent with previous studies (see Salwani et al., 2009), (Zhu et al., 2006). This implies that firms in the tourism industry generally lack appropriate in-house technical skills and pay little attention to developing their knowledge of e-commerce technologies. Kamuzora (2005) found that approximately $27 \%$ of SMEs design their own websites, whereas about $50 \%$ have their websites designed and maintained by IT vendors. Technology competence results also suggest that pressure intensity and perceived benefits were important drivers of e-commerce use, whereas barriers to e-commerce use hindered the intensity of ecommerce use.

This study contributes to the literature in the following ways. First, the study addresses the gap in the literature on the postadoption use of e-commerce in developing countries by focusing on Tanzania. Most studies of e-commerce have considered developed countries and no study have examined the post-adoption use of e-commerce in the context of Tanzania's tourism industry.

Second, the results suggest that Tanzania should improve relevant environments to increase e-commerce use in its tourism industry. First, Tanzania should reduce various barriers to e-commerce use by creating appropriate legal and regulatory frameworks that not only protect consumers, organizations, and intellectual property rights but also enforce contractual obligations, which in turn should increase both organizations' and customers' willingness and confidence to engage in online transactions. Second, the government should coordinate the efforts of firms providing data communications services to achieve low-cost, highcapacity connections to the global Internet. Finally, the findings of this study can be used by firms in the tourism industry as guides to assessing their weaknesses and strengths in terms of e-commerce use.

\section{Conclusion and future research}

In this study, two related questions were investigated: What are the factors influencing the intensity of post-adoption ecommerce use in firms in Tanzania's tourism industry? How does the intensity of e-commerce use influence firm performance? In the hypothesized model, the authors used four factors (pressure intensity, perceived benefits, technological competence, and barriers to e-commerce use) to address the first question and one factor (the intensity of ecommerce use) for the second one.

The results indicate a significant relationship between the intensity of e-commerce use and firm performance. This suggests that those firms in the tourism industry that are already engaged in e-commerce are well positioned to enjoy myriad e-commerce benefits if they intensify its use. However, the use of the Internet for online business is still in its initial stages, which explains the significant effect of ecommerce use on firm performance.
This study has some limitations. First, although SEM is a valid research methodology, the results of this study should be interpreted with caution because they may not provide a complete picture of the Tanzanian tourism industry. Second, the authors focused on the tourism industry as a whole, but individual segments of the industry may differ from one another in terms of the level and scope of e-commerce use. In this regard, future research should test the hypothesized model by using larger samples or by considering additional factors, including the disaggregation of barriers to ecommerce use into financial, regulatory, and technological barriers. Further, future research may consider specific segments of the tourism industry by disaggregating the industry into various segments such as tour operators, airlines, travel agents, hotels, and restaurants, among others.

\section{Acknowledgement}

This work was supported by Institute for Information \& Communications Technology Promotion(IITP) grant funded by the Korea government(MSIP) (B0101-15-233, Smart Networking Core Technology Development). The authors appreciate helpful comments of anonymous reviewers.

\section{References}

Almeida de Almeida, A.G., Avila, A. \& Boncanoska, V. 2007. 'Promoting e-commerce in developing countries', Internet Governance and Policy Working Papers. Available [online] http://www.euromed.net/poolbin.asp?IDPool=454.

Barkley, D.L., Lamie, D.R. \& Markley, D.M. 2007. 'Case studies of e-commerce in small and medium-sized enterprises: a review of the literature', UCED Working Paper 10-2007-01, EDA University Center for Economic Development.

Bresnahan, T.F., Brynjolfsson, E. \& Hitt, M.L. 2002. 'Information technology, workplace organization, and the demand of skilled labor: Firm-level evidence', Quarterly Journal of Economics, 117: 339-76.

Byrne, M.B. 2001. 'Structural Equation Modeling with AMOS: Basic Concepts, Applications, and Programming', Lawrence Erlbaum Associates, Publishers, New Jersey.

Cheng, S. \& Cho, V. 2010. 'An integrated model of employees' behavioral intention toward innovative information and communication technologies in travel agents', Journal of Hospitality \& Tourism Research, 35(4): 488-510.

Elly, T.\& Boter, H. 2011. 'Increasing the competitive strengths of Tanzanian tourism firms-the strategic role of information technology', Available [online] http://www.icsb2011.org/ download/18.62efe22412f41132d41800011474/739.pdf.

Gibbs, J.L. \& Kraemer, K.L. 2010. ‘A cross-country investigation of the determinants of scope of e-commerce use: an institutional approach', Electronic Markets, 14(2): 124-37.

Government of Tanzania. 2003. 'National Information and Communications Technologies Policy', Government Printers, Dar es Salaam. 
Gunasekaran, A. \& Ngai, E.W.T. 2005. 'E-commerce in Hong Kong: An empirical perspective and analysis', Internet Research, 15(2): 141-59.

Hung, Y., Yang, Y., Yang, H. \& Chuang, Y. 2011. 'Factors affecting the adoption of e-commerce for the tourism industry in Taiwan', Asia Pacific Journal of Tourism Research, 16(1): 105-19.

Kamuzora, F. 2005. 'The internet as an empowering agent for small, medium and micro tourism enterprises in poor countries', e-Review of Tourism Research(eRTR), 3(4): 82-90.

Kourtit, K., Nijkamp, P., van Leeuwen, E.S. \& Bruinsma, F. 2011. 'Evaluation of cyber-tools in cultural tourism', International Journal of Sustainable Development, 14(3/4): 179-205.

Kraemer, K.L. \& Gibbs, J.D. 2005. 'Impacts of globalization on ecommerce use and firm performance: a cross-country investigation', The Information Society, 21: 323-40.

Kuang, Z. \& Xu, S. 2008. 'The research of e-commerce capability and Business performance: A resource-based view', International Conference on Management of e-commerce and e-government, Jiangxi China.

Lunogelo, H.B., Mbilinyi, A. \& Hangi, M. 2009. 'The global financial crisis and Tanzania: Effects and policy responses', The Economics \& Society Research Foundation, Dar es Salaam.

Maswera, T., Dawson, R. \& Edwards, J. 2008. 'E-commerce adoption of travel and tourism organizations in South Africa, Kenya, Zimbwabwe and Ugand $a$, Telematics \& Informatics, (25): 187200.

Molla, A. \& Heeks, R. 2007. 'Exploring e-commerce benefits for business in a developing country', The Information Society, 23: 95108.

Oreku, G.S., Kimeli, K. \& Mtenzi, F.J. 2009. 'State of Tanzania ereadiness and e-commerce: Overview', Information Technology for Development, 14(4): 302-11.

OECD. 2004. 'ICT, e-business and SMES', OECD, Paris.

OECD. 2005. 'Guide to measuring the information society', OECD, Paris.

Pflughoet, K.A., Ramamurthy, K., Soofi, E.S., Yasai-Ardekani, M. \& Zahedi, F.M. 2003. 'Multiple conceptualizations of small business web use benefits', A Journal of the Decision Sciences Institute, 34(3): 467-512.

Prewitt, E. 2002. 'Build customer loyalty in an internet world', Available [online] http://www.cio.com/archive/010102/loyalty_ content.html.

Quaddus, M. \& Achjari, D. 2005. 'A model for electronic commerce success', Telecommunucations Policy, 29: 127-52.

Salwani, M.I., Marthandan, G., Norzaidi, M.D. \& Chong, S.C. 2009. 'E-commerce usage and business performance in the Malaysian tourism sector: empirical analysis', Information Management \& Computer Seciruty, 17(2): 166-85.

Schumacker, E.R. \& Lomax, G.R. 2004. A Beginner's Guide to Structural Equation Modeling. $2^{\text {nd }}$ Ed. Lawrence Erlbaum Associates. Publishers. London.
Sulaiman, A. 2000. 'The status of e-commerce applications in Malaysia', Information Technology for Development, 9: 153-61.

Tetelman, M. 2003. Foundations of electronic commerce, model of use. Available [online] http://learnlink.aed.org/Publications/ Sourcebook/chapter5/Foundations_ecommerce_modelofuse.pdf.

Vicente, M.R. \& López, A.J. 2009. 'To what extent firms are using e-commerce? Some evidence for the EU-27', Available [online] ftp://ftp.zew.de/pub/zewdocs/veranstaltungen/ICT2009/papers/Vic ente.pdf.

Yuan, Y., Gretzel, U. \& Fesenmaier, D.R. 2003. 'Internet technology use by American convention and visitors bureaus', Journal of Travel Research, 41: 240-55.

Yoon, Y. \& Uysal, M. 2005. 'An examination of effects of motivation and satisfaction on destination loyalty: a structural model', Tourism Management, 26: 45-56.

Yoon, Y. 2002. 'Development of a structural model for tourism destination competitiveness from stakeholders' perspective', Doctoral Dissertation, Virginia Polytechnic and State University, USA.

Zhu, K. \& Kraemer, K.L. 2005. 'Post-adoption variations in usage and value of e-business by organizations: Cross-country evidence from the retail industry', Information Systems Research, 16(1): 6184.

Zhu, K. \& Kraemer, K.L. 2002. 'E-commerce metrics for netenhanced organizations: assessing the value of e-commerce to firm performance in the manufacturing sector', Information Systems Research, 13(3): 275-95.

Zhuang, Y. \& Lederer, A.L. 2006. 'A resource-based view of electronic commerce', Information \& Management, 43: 251-61.

Zhu, K., Dong, S., Xu, S.X. \& Kraemer, K.L. 2006. 'Innovation diffusion in global contexts: determinants of post-adoption digital transformation of European companies', European Journal of Information Systems, 15: 601-16.

\section{Appendix}

PR1: Most of our suppliers use the internet for business transactions.

PR2: Most of our competitors employ online transactions.

PR3: Our organization uses the Internet to meet customers' demands for electronic business.

PB4: Using e-commerce can expand markets for existing products/services.

PB5: Using e-commerce can open new markets.

PB6: Using e-commerce can reduce operational costs and improve efficiency.

PB7: Using e-commerce can improve coordination with customers and suppliers.

TC8: Our organization has personnel with enough knowledge about e-commerce technologies.

TC9: Our organization has enough technical personnel.

BR10: Annual operating costs of e-commerce are too high for our organization to afford them.

BR12: Our organization is very concerned about data security and online transactions. 
BR13: Our customers are very concerned about data security and privacy in online transactions.

BR14: No appropriate legal framework exists for conducting e-commerce.

SC15: Our organization makes extensive use of the Internet for customer service and support

SC16: Our organization makes extensive use of the Internet for marketing and advertising.

SC18: Our organization uses the Internet for online sales.

SC19: Our organization uses the Internet more to exchange operational data with business customers than to exchange operational data with suppliers

EV21: E-commerce applications have led to more efficient internal processes.

EV22: The use of e-commerce has improved our delivery of customer service.

EV23: The use of e-commerce has increased our sales.

EV24: The use of e-commerce has increased our competitive position in the industry.

EV25: The use of e-commerce has improved our overall business performance. 
